\title{
Predicting Managers' Mental Health Across Countries \\ Using Country-Level COVID-19 Statistics
}

\author{
Lun Li ${ }^{1}$, Stephen X. Zhang ${ }^{2}$, Lorenz Graf-Vlachy ${ }^{3}$ \\ ${ }^{1} \mathrm{PhD}$. candidate, School of Economics and Management, Tsinghua University, Beijing, China \\ ${ }^{2}$ Associate professor, PhD., Adelaide Business School, University of Adelaide, Adelaide, \\ Australia \\ ${ }^{3}$ Professor, PhD., TU Dortmund University, Dortmund, Germany \& ESCP Business School, \\ Berlin, Germany
}

\section{Abstract \\ Background:}

There is limited research focusing on publicly available statistics on the Coronavirus disease 2019 (COVID-19) pandemic as predictors of mental health across countries. Managers are at risk of suffering from mental disorders during the pandemic because they face particular hardship.

\section{Objective:}

We aim to predict mental disorder (anxiety and depression) symptoms of managers across countries using country-level COVID-19 statistics.

\section{Methods:}

A two-wave online survey of 406 managers from 26 countries was finished in May and July 2020. We used logistic panel regression models for our main analyses and performed robustness checks using ordinary least squares regressions. In the sample of 406 managers from 
26 countries, $26.5 \%$ of managers reached the cut-off levels for anxiety (General Anxiety

Disorder-7; GAD-7) and 43.5\% did so for depression (Patient Health Questionnaire-9; PHQ-9)

symptoms.

\section{Findings:}

We found that cumulative COVID-19 statistics (e.g., cumulative cases, cumulative cases per million, cumulative deaths, and cumulative deaths per million) predicted managers' anxiety and depression symptoms positively, whereas daily COVID-19 statistics (daily new cases, smoothed daily new cases, daily new deaths, smoothed daily new deaths, daily new cases per million, and smoothed daily new cases per million) predicted anxiety and depression symptoms negatively. In addition, the reproduction rate was a positive predictor, while stringency of governmental lockdown measures was a negative predictor. Individually, we found that the cumulative count of deaths is the best single predictor of both anxiety and depression symptoms.

\section{Conclusions:}

Cumulative COVID-19 statistics predicted managers' anxiety and depression symptoms positively, while non-cumulative daily COVID-19 statistics predicted anxiety and depression symptoms negatively. Cumulative count of deaths is the best single predictor of both anxiety and depression symptoms. Reproduction rate was a positive predictor, while stringency of governmental lockdown measures was a negative predictor.

\section{Keywords:}

Managers; mental disorders; cumulative deaths; COVID-19; cross-country 
medRxiv preprint doi: https://doi.org/10.1101/2021.07.18.21260567; this version posted July 22, 2021. The copyright holder for this preprint (which was not certified by peer review) is the author/funder, who has granted medRxiv a license to display the preprint in perpetuity.

It is made available under a CC-BY-NC-ND 4.0 International license. 


\section{Introduction}

Since the outbreak of COVID-19, many studies have examined the pandemic's influence on the general public's mental health in various countries ${ }^{1-3}$. This stream of research predominantly studied predictors of mental health at the individual level, for example, demographic characteristics ${ }^{4,5}$.

Further, scholars have recently begun to focus on the mental health of specific groups, for example, students ${ }^{6}$ and healthcare workers ${ }^{2,3,7}$. However, this research again studies non-country-level predictors and, critically, there is hardly any research focused on the specific group of managers ${ }^{8}$. This is problematic because managers perform one of the most stressful and consequential jobs ${ }^{9,10}$. For one, during a pandemic, managers cannot manage as usual, and they may thus suffer particularly due to the decision-making and leadership responsibilities they must exercise during such a time of crisis ${ }^{11}$. For another, managers' mental health may also have important second-order effects on their subordinates' lives and therefore their subordinates' mental health ${ }^{8}$.

Further, the majority of research on mental health during COVID-19 uses cross-sectional data $^{1,4,12}$, and there exists no cross-country research studying the link between the severity of the pandemic and managers' mental health. It is thus novel and likely practically useful to track changes in managers' mental health and identify the best predictors for it ${ }^{13}$.

This research aims to use country-level COVID-19 statistics to predict managers' anxiety and depression symptoms using two-wave online survey data. It is among the first to focus on the group of vulnerable managers ${ }^{8}$, and the first to do so using longitudinal data. We first 
examine the predictive power of different country-level pandemic severity statistics and then compare their differential effects to identify the strongest predictor of mental health issues.

\section{Methods}

\section{Sample and procedure}

We implemented a two-wave online survey to collect data from managers. Respondents to our survey are former consultants of a global management consulting firm who moved into managerial roles after consulting. After dropping observations that had missing data in our country-level predictors, we had a total of 812 usable responses from 406 managers. Mean levels of anxiety and depression symptoms varied substantially across countries and over time in our sample. For example, the prevalence of anxiety and depression symptoms for the US was $13 \%$ and 14\%, respectively, on May 2, 2020, and 52\% and 79\%, respectively, on June 17, 2020. In contrast, the prevalence of anxiety and depression for Japan was $0 \%$ on May 2, 2020; and the prevalence of anxiety and depression for Japan was $20 \%$ and $80 \%$ on June 17,2020 , respectively. All managers participated voluntarily in the survey, which they could terminate at any time, and were not compensated. The survey got ethics approval (\#2020-04-01 and \#2020-06-01) from Pramuan Bunkanwanicha, associate dean for research at ESCP Business

School.

\section{Measures}

We collected socio-demographic information, including gender, age, educational level, and number of children. We obtained cumulative counts of confirmed cases, cumulative counts 
of confirmed cases per million, cumulative counts of deaths, cumulative counts of deaths per million, daily counts of new confirmed cases, daily counts of new deaths, daily counts of new confirmed cases per million, and daily counts of new deaths per million for each country from the Coronavirus Resource Center (CRC) at Johns Hopkins University. All data was obtained for the exact day each manager responded to the survey. We calculated smoothed values of daily counts of new confirmed cases, daily counts of new deaths, daily counts of new confirmed cases per million, and daily counts of new deaths per million by taking the mean of the daily values in the week prior to managers' responses. All absolute cumulative counts and daily new counts were log-transformed to account for the skewed distribution of the data. We obtained the reproduction rate of COVID-19 and a stringency index that measures the strictness of governments' lockdown policies for each country from Roser, Ritchie, Ortiz-Ospina, \& Hasell ${ }^{14}$. This stringency index comprises nine indicators, including school closures, workplace closures, and travel bans, and ranges from 0 (no policies) to 100 (very strict policies). To control for potential general country effects on mental health, we also consider population density and gross domestic product (GDP) per capita and obtained corresponding data from the World Bank.

We measured anxiety using the generalized anxiety disorder (GAD-7) instrument, which consists of seven questions $(\alpha=.88)$, with a cutoff of 10 or greater indicating anxiety disorder symptoms ${ }^{15}$. Depression was assessed using the Patient Health Questionnaire (PHQ-9), which consists of nine questions $(\alpha=.83)$, with a cutoff of 10 or greater indicating depression disorder symptoms ${ }^{16,17}$. 
As our data on individuals' mental health is nested in the two-wave survey across 26 countries, we employed panel analysis ${ }^{18}$. Specifically, we ran panel logistic regression using analyses Stata 17 to predict managers' mental health issues at a significance level of 0.05 .

\section{Patient and public involvement}

Our research did not involve patients or the public in the design, conduct, reporting, or dissemination plans.

\section{Results}

\section{Descriptive findings}

Table 1 and Table 2 present descriptive statistics of the sampled managers and COVID-19 severity statistics across different countries. The mean scores of anxiety (GAD-7) and depression (PHQ-9) were $0.26(\mathrm{SD}=0.44)$ and $0.43(\mathrm{SD}=0.50)$, respectively. Overall, the proportion of our sampled participants with anxiety disorder symptoms is much lower $(\mathrm{p}=0.000)$ in the first-wave survey on May 2, 2020 (7.6\%) compared to the second-wave survey on June 17, $2020(45.3 \%)$. Similarly, the prevalence of depression disorder symptoms is much lower $(p=0.000)$ in the first-wave survey $(8.1 \%)$ compared to the second-wave survey $(78.8 \%)$.

\section{[Insert Tables 1 and 2 about here]}

Of the 406 managers, $75.4 \%$ (306) were male. All held at least bachelor's degrees. Age ranged from 29 to 78 years. Most managers $(40.2 \%)$ had no children. For about half of the participants (44.6\%), their countries' population density ranged between 1 and 100. GDP per capita in the countries of most managers (69.5\%) ranged from 40,000 to 60,000 (constant 2011 
medRxiv preprint doi: https://doi.org/10.1101/2021.07.18.21260567; this version posted July 22, 2021. The copyright holder for this preprint (which was not certified by peer review) is the author/funder, who has granted medRxiv a license to display the preprint in perpetuity.

It is made available under a CC-BY-NC-ND 4.0 International license .

US dollars). The reproduction rate of the COVID-19 epidemic ranged from 0.51 to 1.50 , and the stringency index ranged from 28.7 to 96.3 across the 26 countries over the survey waves.

\section{Predictors of managers' mental health}

As presented in Tables 3 and 4, female managers were more likely than male managers to exhibit anxiety and depression symptoms. Age negatively predicted managers' anxiety and depression. The effects of education level and the number of children were not significant.

More importantly, Model 2 in both Table 3 and Table 4 shows that cumulative confirmed cases positively predicted managers' anxiety ( $b=5.42 ; 95 \%$ CI: 3.92 to $6.91 ; p<0.001)$ and depression ( $b=8.11 ; 95 \%$ CI: 6.81 to 9.41; $\mathrm{p}<0.001)$ symptoms. Model 3 in Table 3 and Table 4 shows that cumulative confirmed cases per million positively predicted managers' anxiety $(b=0.00 ; 95 \%$ CI: 0.001 to $0.002 ; p<0.001)$ and depression ( $b=0.00 ; 95 \%$ CI: 0.002 to 0.002 ; p $<0.001$ ) symptoms. Similarly, Model 4 in both Table 3 and Table 4 shows that cumulative deaths positively predicted anxiety $(b=6.42 ; 95 \% \mathrm{CI}: 4.70$ to $8.15 ; \mathrm{p}<0.001)$ and depression $(b=9.22 ; 95 \%$ CI: 7.88 to $10.55 ; \mathrm{p}<0.001)$ symptoms, and Model 5 in Tables 3 and 4 shows that cumulative deaths per million also positively predicted symptoms of these disorders $(b=0.02$;

95\% CI: 0.02 to $0.03 ; \mathrm{p}<0.001$ and $\mathrm{b}=0.04 ; 95 \%$ CI: 0.03 to $0.04 ; \mathrm{p}<0.001)$.

Interestingly, Models 6 to 15 in Tables 3 and 4 show that new confirmed cases negatively predicted managers' anxiety $(\mathrm{b}=-0.96 ; 95 \% \mathrm{CI}:-1.30$ to $-0.61 ; \mathrm{p}<0.001)$ and depression $(b=-1.52 ; 95 \%$ CI: -1.85 to $-1.20 ; \mathrm{p}<0.001)$ symptoms. Smoothed new confirmed cases negatively predicted managers' mental anxiety ( $b=-1.47 ; 95 \%$ CI: -1.88 to $-1.06 ; \mathrm{p}<0.001)$ and depression ( $b=-2.32 ; 95 \%$ CI: -2.71 to $-1.92 ; p<0.001)$ symptoms. In addition, daily new deaths 
medRxiv preprint doi: https://doi.org/10.1101/2021.07.18.21260567; this version posted July 22, 2021. The copyright holder for this preprint

negatively predicted the occurrence of anxiety $(b=-1.18 ; 95 \% \mathrm{CI}:-1.51$ to $-0.84 ; \mathrm{p}<0.001)$ and depression ( $b=-1.82 ; 95 \%$ CI: -2.11 to $-1.52 ; \mathrm{p}<0.001)$ symptoms, respectively. Smoothed daily deaths negatively predicted anxiety $(b=-1.55 ; 95 \% \mathrm{CI}:-1.94$ to $-1.15 ; \mathrm{p}<0.001)$ and depression $(b=-2.45 ; 95 \% \mathrm{CI}:-2.80$ to $-2.09 ; \mathrm{p}<0.001)$ symptoms. We found corroborating evidence using population-adjusted predictors, i.e., new confirmed cases per million, smoothed new cases per million, new deaths per million, and smoothed new deaths per million.

The reproduction rate of COVID-19 positively predicted managers' anxiety $(b=6.20 ; 95 \%$ CI: 4.46 to $7.94 ; \mathrm{p}<0.001)$ and depression ( $b=9.00 ; 95 \%$ CI: 7.23 to $10.77 ; \mathrm{p}<0.001)$ symptoms. Interestingly, the stringency index negatively predicted anxiety $(b=-0.18 ; 95 \% \mathrm{CI}:-0.23$ to $-0.13 ; \mathrm{p}<0.001)$ and depression $(\mathrm{b}=-0.29 ; 95 \% \mathrm{CI}:-0.34$ to $-0.24 ; \mathrm{p}<0.001)$ symptoms.

Finally, we compared the relative goodness fit of all models that include more predictors than the baseline Model 1 in Tables 3 and 4. The cumulative count of deaths emerged as the best predictor of managers' anxiety symptoms since both AIC and BIC for Model 4 were lower than for any alternative model. The cumulative count of deaths was also the best predictor of managers' depression symptoms.

[Insert Tables 3 and 4 about here]

Furthermore, we ran supplemental ordinary least squares (i.e., multiple regression) models predicting the absolute severity scores of GAD-7 and PHQ-9 as a robustness check. The results, which are fully consistent with the findings discussed above, are presented in Tables 5 and 6.

[Insert Tables 5 and 6 about here] 
As an additional robustness check, we re-ran all models while including measures for firm size as well as firms' changes in revenues and profits due to COVID-19. None of these additional predictors were significant, and none of the other results changed.

\section{Discussion}

This paper-which is the first to join public country-level COVID-19 statistics with a primary cohort cross-country survey to predict managers' mental disorders across countries—offers several insights that may help psychiatric screening efforts.

First off, consistent with prior studies on other populations ${ }^{6,19,20}$, gender and age were predictors of anxiety and depression symptoms in managers. For one, female managers were more likely to suffer from mental health problems than male managers. This is in line with the general literature on gender risk for mental health issues, which outlines various risk factors such as social expectations and biological givens that may explain a generally greater vulnerability of females ${ }^{19-21}$. This literature also highlights the important role of stressful life events ${ }^{22}$, which might of course have become more frequent during a pandemic. Our findings are further consistent with the emerging body of literature specific to the impact of COVID-19, which suggests that females may have a particular underlying vulnerability to negative emotions ${ }^{13,23}$ and are concerned more about economic burdens ${ }^{23,24}$ during the pandemic, compared to their male counterparts. All these factors may of course also promote mental health issues in female managers. For another, younger managers in our sample experienced greater mental distress, potentially because younger managers might have less experience with crisis situations and might thus have developed fewer coping techniques. Again, this finding is 
compatible with prior literature ${ }^{5,25}$. Our findings thus advise medical professionals to target younger and female managers with mental health service offerings. Notably, other predictors found in the literature, such as education ${ }^{26}$ or the number of children ${ }^{27}$, failed to predict mental health problems among managers across countries.

More importantly, this study examined country-level COVID-19 severity statistics as predictors of managers' mental health. As mentioned before, managers are a largely neglected vulnerable population that bears responsibility for guiding subordinates, potentially impacting the lives - and the mental health—of many ${ }^{8}$. Our findings indicate that cumulative confirmed cases and deaths positively predict anxiety and depression symptoms for those managers during the COVID-19 pandemic, while daily new confirmed cases and deaths negatively predict these mental disorders. Surprisingly, thus, cumulative counts and daily new counts have differential predictive power regarding managers' mental health. The finding that cumulative counts are positively related with symptoms of mental health issues is fairly intuitive, since a growing cumulative count indicates that the overall magnitude of the COVID-19 crisis as an ongoing historic event increases. Managers might thus be adversely affected by the cumulation of pandemic-related stressors like lockdown measures over time ${ }^{28}$. The finding regarding new daily counts is somewhat less intuitive and does not have any precedent in the literature, making it all the more intriguing. The likely most plausible explanation is that managers observing higher daily new counts anticipate satisfactory government intervention, possibly leading to a reduction in concerns over the situation ${ }^{29}$. An alternative explanation would be that managers, frequently working remotely during the pandemic, are reminded of their privileged 
positions by seeing that while daily new counts wreak havoc elsewhere, they themselves and their closer environments have thus far not been affected. This could lead to positive effects on mental health by way of downward comparison with less fortunate workers ${ }^{30,31}$.

Further, the virus reproduction rate positively predicts managers' anxiety and depression, which is intuitive because it directly reflects the speed of spread of COVID-19 and might thus affect the perception of whether the pandemic is controllable. Such control perceptions have repeatedly been linked to mental health consequences ${ }^{32-34}$. Again possibly surprisingly, however, the stringency index negatively predicted managers' mental disorders. In line with our speculation above, this might indicate that measures like school closures, workplace closures, and travel bans can assure people that the crisis is being dealt with and thus decrease managers' concerns about becoming infected or concerns about managing uncertainty in the workplace. This finding is novel compared to previous studies focusing on the general public ${ }^{35,36}$. A possible explanation is that we concentrate on a population with specific skills and views ${ }^{37-39}$ that may thus interpret and cope with different indicators differently than the general population.

Finally, we identified cumulative deaths as the best predictor for managers' mental health among the studied variables. Thus, healthcare service providers and human resource departments of multinational companies might particularly wish to use this simple and readily available statistics to prioritize help offerings to managers, at least in the earlier phases of a pandemic. Specifically, multinational companies might want to offer personal protective equipment, online consultation including cognitive behavioral therapy, or telemedicine 
services to their managers or provide them with other wellness resources to manage stress and improve coping, including workshops and self-help groups to reduce workplace-related

stressors ${ }^{40,41}$. Such measures could provide managers with effective coping techniques like problem-focused coping (e.g., planning on what to change about the situation), self-supported emotional coping (e.g., learning to live with the situation), and social-support emotional coping (e.g., getting emotional support from others) ${ }^{42}$.

\section{Limitations and future research}

There are several limitations to this study. First, we only collected two waves of data, restricting our ability to make causal claims. Although it is a cohort study, future scholars may track individuals' mental health over more waves with shorter intervals. Second, respondents were alumni of one of the most selective consulting firms in the world. Others might thus wish to replicate our findings in different manager populations to ensure generalizability. Third, our survey was voluntary, so the response rate was limited, and it is possible that managers with severe mental illness might not have responded in the first place. The generalizability of our findings might thus be restricted. Fourth, we collected only limited data on the organizations the managers were working in. This implies that future researchers might fruitfully replicate our research while, for example, accounting explicitly for organizations' specific responses to the pandemic including any organizational support managers might have received. Fifth, this study aims to explore epidemic statistics as predictors of mental health, and as the first study to do so with the aim of helping psychiatric screening, we did not extensively explore the possible mechanisms leading to mental health disorders. Our findings thus call for future research to 
examine the relationship between epidemic statistics and mental health beyond psychiatric screening purposes.

\section{Conclusions}

In conclusion, this study identified readily available country-level pandemic statistics as predictors of managers' mental health disorder symptoms. Specifically, cumulative COVID-19 statistics predict symptoms positively, while non-cumulative daily statistics predict the same symptoms negatively. The reproduction rate and the stringency index of each country also predicted mental health. These identified country-level predictors can be instrumental for mental health organizations and policymakers to optimize resource allocation and mobilization across geographies during the COVID-19 pandemic. 
medRxiv preprint doi: https://doi.org/10.1101/2021.07.18.21260567; this version posted July 22, 2021. The copyright holder for this preprint (which was not certified by peer review) is the author/funder, who has granted medRxiv a license to display the preprint in perpetuity.

It is made available under a CC-BY-NC-ND 4.0 International license .

\section{References}

1. Jahanshahi AA, Dinani MM, Madavani AN, Li J, Zhang SX. The distress of Iranian adults during the Covid-19 pandemic - More distressed than the Chinese and with different predictors. Brain Behav Immun. 2020;87:124-125. doi:10.1016/j.bbi.2020.04.081

2. Debes JD, Quadri NS, Sultan A, et al. Risk of healthcare worker burnout in Africa during the COVID-19 pandemic. Ann Glob Health. 2021;87(1):5. doi:10.5334/aogh.3150

3. Liu Z, Wu J, Shi X, et al. Mental health status of healthcare workers in China for COVID-19 epidemic. Ann Glob Health. 2020;86(1):128. doi:10.5334/aogh.3005

4. Zhang SX, Chen J, Jahanshahi AA, et al. Succumbing to the COVID-19 pandemic: healthcare workers not satisfied and intend to leave their jobs. medRxiv. Published online May 24, 2020:2020.05.22.20110809. doi:10.1101/2020.05.22.20110809

5. Abir T, Kalimullah NA, Osuagwu UL, et al. Prevalence and factors associated with mental health impact of COVID-19 pandemic in Bangladesh: a survey-based cross- sectional study. Ann Glob Health. 2021;87(1):43. doi:10.5334/aogh.3269

6. Ghandour R, Ghanayem R, Alkhanafsa F, et al. Double burden of COVID-19 pandemic and military occupation: mental health among a Palestinian university community in the west bank. Ann Glob Health. 2020;86(1):131. doi:10.5334/aogh.3007

7. Yáñez JA, Afshar Jahanshahi A, Alvarez-Risco A, Li J, Zhang SX. Anxiety, distress, and turnover intention of healthcare workers in Peru by their distance to the epicenter during the COVID-19 crisis. Am J Trop Med Hyg. 2020;103(4):1614-1620. doi:10.4269/ajtmh.20-0800

8. Graf-Vlachy L, Sun S, Zhang SX. Predictors of managers' mental health during the COVID-19 pandemic. Eur J Psychotraumatology. 2020;11(1):1834195. doi:10.1080/20008198.2020.1834195

9. Egede LE, Ruggiero KJ, Frueh BC. Ensuring mental health access for vulnerable populations in COVID era. J Psychiatr Res. 2020;129:147-148. doi:10.1016/j.jpsychires.2020.07.011

10. Ivancevich JM, Matteson MT, Preston C. Occupational stress, type a behavior, and physical well being. Acad Manage J. 1982;25(2):373-391. doi:10.5465/255998

11. Palmer S. Managers more likely to be diagnosed with a mental health condition than other employees. People Management.

https://www.peoplemanagement.co.uk/news/articles/managers-more-likely-diagnosed-m ental-health-condition-other-employees. Published October 8, 2019. Accessed November 7, 2020.

12. Ke Y-T, Hung C-H. Factors that affect the health status of health care providers-A cross-sectional design. J Nurs Manag. 2020;28(6):1199-1206. doi:10.1111/jonm.13057

13. Daly M, Sutin AR, Robinson E. Longitudinal changes in mental health and the COVID-19 pandemic: evidence from the UK Household Longitudinal Study. Psychol Med. Published online 2020:1-10. doi:10.1017/S0033291720004432

14. Roser M, Ritchie H, Ortiz-Ospina E, Hasell J. Coronavirus pandemic (COVID-19). Our World in Data Retrieved from: https://ourworldindata.org/coronavirus. Published online March 4, 2020. Accessed December 19, 2020. https://ourworldindata.org/coronavirus 
medRxiv preprint doi: https://doi.org/10.1101/2021.07.18.21260567; this version posted July 22, 2021. The copyright holder for this preprint (which was not certified by peer review) is the author/funder, who has granted medRxiv a license to display the preprint in perpetuity. It is made available under a CC-BY-NC-ND 4.0 International license .

15. Spitzer RL, Kroenke K, Williams JBW, Löwe B. A brief measure for assessing generalized anxiety disorder: the GAD-7. Arch Intern Med. 2006;166(10):1092. doi:10.1001/archinte.166.10.1092

16. Kroenke K, Spitzer RL, Williams JBW, Löwe B. The patient health questionnaire somatic, anxiety, and depressive symptom scales: a systematic review. Gen Hosp Psychiatry. 2010;32(4):345-359. doi:10.1016/j.genhosppsych.2010.03.006

17. Kroenke K, Spitzer RL, Williams JBW. The PHQ-9. J Gen Intern Med. 2001;16(9):606-613. doi:10.1046/j.1525-1497.2001.016009606.x

18. Hsiao C. Analysis of Panel Data. 3rd ed. Cambridge University Press; 2014. Accessed November 7, 2020.

https://www.cambridge.org/core/books/analysis-of-panel-data/A774C63FF969DA1944 A3F91501702C65

19. Kinrys G, Wygant LE. Anxiety disorders in women: does gender matter to treatment? Braz J Psychiatry. 2005;27:s43-s50. doi:10.1590/S1516-44462005000600003

20. Remes O, Brayne C, Linde R van der, Lafortune L. A systematic review of reviews on the prevalence of anxiety disorders in adult populations. Brain Behav. 2016;6(7):e00497. doi:10.1002/brb3.497

21. Seeman MV. Mental illness in women. In: Women and Health. Elsevier; 2000:989-996.

22. Kendler KS, Kessler RC, Neale MC, Heath AC, Eaves LJ. The prediction of major depression in women: toward an integrated etiologic model. Am J Psychiatry. 1993;150:1139-1139. doi:10.1176/ajp.150.8.1139

23. Xiong J, Lipsitz O, Nasri F, et al. Impact of COVID-19 pandemic on mental health in the general population: A systematic review. J Affect Disord. 2020;277:55-64. doi:10.1016/j.jad.2020.08.001

24. Almeida M, Shrestha AD, Stojanac D, Miller LJ. The impact of the COVID-19 pandemic on women's mental health. Arch Womens Ment Health. 2020;23(6):741-748. doi:10.1007/s00737-020-01092-2

25. Wang SSY, Teo WZY. Equitable and holistic public health measures during the Singaporean COVID-19 pandemic. Ann Glob Health. 2021;87(1):45. doi:10.5334/aogh.3244

26. Zhang SX, Wang Y, Rauch A, Wei F. Unprecedented disruption of lives and work: Health, distress and life satisfaction of working adults in China one month into the COVID-19 outbreak. Psychiatry Res. 2020;288:112958. doi:10.1016/j.psychres.2020.112958

27. Ahmad A, Rahman I, Agarwal M. Early psychosocial predictors of mental health among Indians during coronavirus disease 2019 outbreak. J Health Sci. 2020;10(2):147-156. doi:10.17532/jhsci.2020.950

28. Pierce M, Hope H, Ford T, et al. Mental health before and during the COVID-19 pandemic: a longitudinal probability sample survey of the UK population. Lancet Psychiatry. 2020;7(10):883-892. doi:10.1016/S2215-0366(20)30308-4

29. Mækelæ MJ, Reggev N, Dutra N, et al. Perceived efficacy of COVID-19 restrictions, reactions and their impact on mental health during the early phase of the outbreak in six countries. R Soc Open Sci. 2020;7(8):200644. doi:10.1098/rsos.200644 
medRxiv preprint doi: https://doi.org/10.1101/2021.07.18.21260567; this version posted July 22, 2021. The copyright holder for this preprint (which was not certified by peer review) is the author/funder, who has granted medRxiv a license to display the preprint in perpetuity. It is made available under a CC-BY-NC-ND 4.0 International license .

30. VanderZee KI, Buunk BP, Sanderman R. Social comparison as a mediator between health problems and subjective health evaluations. Br J Soc Psychol. 1995;34(1):53-65. doi:10.1111/j.2044-8309.1995.tb01048.x

31. Wills TA. Downward comparison as a coping mechanism. In: Snyder CR, Ford CE, eds. Coping with Negative Life Events: Clinical and Social Psychological Perspectives. The Plenum Series on Stress and Coping. Springer US; 1987:243-268. doi:10.1007/978-1-4757-9865-4_10

32. Hovenkamp-Hermelink JHM, Jeronimus BF, van der Veen DC, et al. Differential associations of locus of control with anxiety, depression and life-events: A five-wave, nine-year study to test stability and change. J Affect Disord. 2019;253:26-34. doi:10.1016/j.jad.2019.04.005

33. Southwick FS, Southwick SM. The loss of a sense of control as a major contributor to physician burnout: a neuropsychiatric pathway to prevention and recovery. JAMA Psychiatry. 2018;75(7):665-666. doi:10.1001/jamapsychiatry.2018.0566

34. Wierenga KL, Moore SE, Pressler SJ, Hacker ED, Perkins SM. Associations between COVID-19 perceptions, anxiety, and depressive symptoms among adults living in the United States. Nurs Outlook. Published online April 5, 2021. doi:10.1016/j.outlook.2021.03.020

35. O'Hara L, Rahim HFA, Shi Z. Gender and trust in government modify the association between mental health and stringency of social distancing related public health measures to reduce COVID-19: a global online survey. medRxiv. Published online July 21, 2020:2020.07.16.20155200. doi:10.1101/2020.07.16.20155200

36. Ssentongo P, Fronterre C, Geronimo A, et al. Tracking and predicting the African COVID-19 pandemic. medRxiv. Published online November 16, 2020:2020.11.13.20231241. doi:10.1101/2020.11.13.20231241

37. Carter JR, Irons MD. Are economists different, and if so, why? J Econ Perspect. 1991;5(2):171-177. doi:10.1257/jep.5.2.171

38. Johnson JEV, Powell PL. Decision making, risk and gender: are managers different? Br J Manag. 1994;5(2):123-138. doi:10.1111/j.1467-8551.1994.tb00073.x

39. Kaplan SN, Sorensen M. Are CEOs Different? Characteristics of Top Managers. National Bureau of Economic Research; 2017. doi:10.3386/w23832

40. Pfefferbaum B, North CS. Mental health and the COVID-19 pandemic. N Engl J Med. 2020;383(6):510-512. doi:10.1056/NEJMp2008017

41. Bhatti OA, Rauf H, Aziz N, Martins RS, Khan JA. Violence against healthcare workers during the COVID-19 pandemic: a review of incidents from a lower-middle-income country. Ann Glob Health. 2021;87(1):41. doi:10.5334/aogh.3203

42. Zheng D, Luo Q, Ritchie BW. Afraid to travel after COVID-19? Self-protection, coping and resilience against pandemic 'travel fear.' Tour Manag. 2021;83:104261.

doi:10.1016/j.tourman.2020.104261 